\title{
Exploring Psychological Constructs as Predictors of Life Satisfaction Among Adolescents with Absentee Parents
}

\author{
Lendi Lee A. Sealmoy ${ }^{1}$ and Noel S. Marañon ${ }^{2}$ \\ ${ }^{1}$ Doña Montserrat Lopez Memorial High School, Silay City, Philippines \\ ${ }^{2}$ Philippine Normal University-Visayas, Cadiz City, Philippines
}

\begin{tabular}{l} 
Article history \\
Submitted: 2 July 2020 \\
Revised: 29 October 2020 \\
Accepted: 12 November 2020 \\
\hline Keywords \\
Guidance and Counseling \\
Life Satisfaction \\
Adolescents \\
Absentee Parents \\
Catholic School \\
Correlational-Predictive \\
Negros Occidental
\end{tabular}

Introduction. Most schools aim to produce holistically developed individuals; however, initiatives fostering life satisfaction and well-being are not substantial or even neglected. Likewise, globally, adolescents are confronted with various situations influencing how they view and evaluate their lives. One of these factors is parental absence. Consequently, this paper describes the degree of grit, the extent of resilience and self-control, and the level of life satisfaction of adolescents with absentee parents. Moreover, it establishes correlations among the three psychological constructs grit, resilience and self-control, and life satisfaction. Furthermore, it explores whether the three constructs predict life satisfaction.

Methods. This study used quantitative design in descriptive, correlational, and predictive approach in assessing the degree of grit, the extent of resilience and self-control, and level of life satisfaction of adolescents with absentee parents in a Catholic school in Northern Negros Occidental during the school year 2019-2020 and in determining whether the three psychological constructs; grit, resilience, and self-control predicts life satisfaction. Through purposive sampling, 133 adolescents were identified and participated in this study by answering standardized self-report questionnaires. Mean, Standard Deviation, Pearson r, and Multiple Regression Analysis were used to analyze data.

Results. The findings of this study revealed that the degree of grit of adolescents with absentee parents regardless of the type of absentee parents and the length of parental absence is moderate. Likewise, a great extent of resilience in adolescents was found irrespective of the type and length of parental absence. Moreover, findings in this study signify a moderate extent of self-control among adolescents regardless of the type and length of parental absence. Furthermore, findings revealed an average level of life satisfaction among adolescents in general and in terms of the length of parental absence. However, in terms of the type of absentee parents, adolescents with absentee mothers have a low level of life satisfaction. In contrast, those adolescents with both parents who are absent and those who have absentee fathers recorded an average level of life satisfaction. With regards to the relationship existing between the three constructs and life satisfaction, only grit and resilience were found to be significantly correlated with life satisfaction. Finally, the predictive analysis revealed that grit, resilience, and self-control collectively predict life satisfaction. However, individual analysis of the constructs indicated that only grit predicts life satisfaction.

Conclusion. The vitality of undermining factors influencing life satisfaction and well-being highlighted in this study, stresses the importance of crafting relevant support programs fostering adolescents' life satisfaction with absentee parents. This poses a challenge to the guidance counselors, as the primary implementer, with the support of the administrators and the teachers to creatively deliver various activities enhancing life satisfaction by fostering grit, resilience, and self-control among these adolescents. This initiative addresses the results in this study, indicating that collectively grit, resilience, and self-control predicts life satisfaction. Likewise, grit and resilience significantly influence life satisfaction, further underscoring the need for the school to support research-based programs in improving adolescents' lives, making significant contributions to society. 
Practical Value of the Paper. This study advances knowledge in this topic and significantly contributes to the growing literature, particularly in the local demographics. Additionally, the findings of this study provide baseline information in creating a support program for adolescents with absentee parents, which in particular, those adolescents with OFW parents that will benefit the counselors, administrators, and future researchers.

\section{References}

Antaramian, S. (2017). The importance of very high life satisfaction for students' academic success. Journal of Cogent Education,4(1). https://doi.org/1080/2331186x.2017.1307622

Bjarnason, T., Bendtsen, P., \& Arnarsson, A. (2010). Life satisfaction among children in different family structures: A comparative study of 36 western societies. Children and Society Journal, 26(1), 51-62. https://doi.org/10.1111/ j.1099-0860.2010.00324.x

Calantas, E. L. L., \& Lobaton, P. I. (2018). Lived experiences of teenagers with overseas Filipino worker parents. International Journal of English and Education, 7(3) Issn: 2278-4012

Dias, P. C., \& Cadime, I. (2017). Protective factors and resilience in adolescents: The mediating role of self-regulation. Psicología Educativa, 23 (1), 37-43. https://doi.org/10.1016/j.pse.2016.09003

Hofmann, W., Luhmann, M., Fisher, R., Vohs, K.D., \& Baumeister, R. F. (2013). Yes, but are they happy? Effects of trait self-control on affective well-being and life satisfaction. Journal of Personality, 82(4), 265-277. https://doi. org/10.1111/jopy.12050

Huang, J., Wang, K. \& Ringel-Kulka, T. (2015). Predictors of life satisfaction among Asian American adolescentsanalysis of add health data. SpringerPlus, 4, 216. https://doi.org/10.1186/s40064-015-1008

Li, J., Fang, M., \& Cheng, Z. (2018). The influence of grit on life satisfaction: Self-esteem as a mediator. Journal of Belgian Association for Psychological Science, 58(1), 51-66. https://doi.org/10.5334/pb400

Suldo, S. M., Minch, D. R., \& Hearon, B. V. (2014). Adolescent life satisfaction and personality characteristics: Investigating relationships using a Five-Factor Model. Journal of Happiness Studies, 16, 965-983. https://doi. org/10.1007/s10902-014-9544-1

Tagay, O., Karatas, Z., Oznur, B., \& Savi, F. (2016). Resilience and life satisfaction as the predictors of general selfefficacy. Global Journal of Guidance and Counseling in Schools: Current Perspectives, 6(1), 011-017.

Vainio, M. M., Daukantaite, D. (2016). Grit and different aspects of well-being: Direct and indirect relationships via sense of coherence and authenticity. Journal of Happiness 17(5), 2119-2147. https://doi.org/10.1007/s10902015-9688-7

\section{Correspondence:}

Lendi Lee A. Sealmoy [sealmoylee@gmail.com]

https://orcid.org/0000-0002-9132-2683 